\title{
Effects of Canagliflozin on Serum Magnesium in Patients With Type 2 Diabetes Mellitus: A Post Hoc Analysis of Randomized Controlled Trials
}

Richard E. Gilbert · Christian Mende · Ujjwala Vijapurkar •

Sue Sha $\cdot$ Michael J. Davies · Mehul Desai

Received: December 14, 2016/Published online: February 14, 2017

(C) The Author(s) 2017. This article is published with open access at Springerlink.com

\section{ABSTRACT}

Introduction: The objective of this study was to evaluate the effects of canagliflozin, a sodium glucose co-transporter 2 inhibitor, on serum magnesium in hypomagnesemic patients with type 2 diabetes.

Methods: This post hoc analysis was based on pooled data from four placebo-controlled studies of canagliflozin $(N=2313)$. The proportion of patients with baseline serum magnesium $<0.74 \mathrm{mmol} / \mathrm{L}$ who achieved serum magnesium $\geq 0.74 \mathrm{mmol} / \mathrm{L}$ at week 26 was evaluated.

Results: At week 26, canagliflozin 100 and $300 \mathrm{mg}$ increased serum magnesium versus placebo in patients with baseline serum

Enhanced content To view enhanced content for this article go to http://www.medengine.com/Redeem/ D687F0600629F7CA.

R. E. Gilbert

St. Michael's Hospital, University of Toronto,

Toronto, ON, Canada

C. Mende

University of California, San Diego, La Jolla, CA, USA

U. Vijapurkar $\cdot$ S. Sha $\cdot$ M. Desai

Janssen Research \& Development, LLC, Raritan, NJ, USA

M. J. Davies ( $\square)$

Janssen Scientific Affairs, LLC, Titusville, NJ, USA e-mail: mdavies9@its.jnj.com magnesium $<0.74 \mathrm{mmol} / \mathrm{L}(17.0 \%$ and $19.0 \%$ vs $3.9 \%)$ and $\geq 0.74 \mathrm{mmol} / \mathrm{L}(4.9 \%$ and $7.0 \%$ vs $-1.4 \%)$. More patients with baseline serum magnesium $<0.74 \mathrm{mmol} / \mathrm{L}$ had serum magnesium $\geq 0.74 \mathrm{mmol} / \mathrm{L}$ at week 26 with canagliflozin 100 and $300 \mathrm{mg}$ versus placebo $(74.1 \%$ and $80.6 \%$ vs $28.8 \%$ ).

Conclusions: Canagliflozin was associated with normalization of serum magnesium in hypomagnesemic patients with type 2 diabetes, potentially leading to improved cardiometabolic outcomes.

Clinical trial registration: ClinicalTrials.gov Identifiers, NCT01081834, NCT01106677, NCT01106625, NCT01106690.

Keywords: Canagliflozin; Cardiometabolic; Cardiovascular disease; Magnesium; Sodium glucose co-transporter; Type 2 diabetes

\section{INTRODUCTION}

Many patients with type 2 diabetes have hypomagnesemia (serum magnesium $<0.74 \mathrm{mmol} / \mathrm{L}$ ); poor intestinal absorption and renal wasting of magnesium have been implicated in the pathophysiology [1]. Hypomagnesemic patients with type 2 diabetes show more rapid disease progression and decline in renal function than those with normal magnesium levels, and they are at increased risk for cardiometabolic complications and chronic kidney disease (CKD) 
[1-3]. Hypomagnesemic patients with type 2 diabetes have reduced pancreatic $\beta$-cell activity and increased insulin resistance, which, in turn, lower serum magnesium levels as part of a "vicious circle" [1]. Hypomagnesemia is also an established risk factor for ventricular arrhythmia, which may be an indicator of future cardiovascular events or sudden cardiac death [4]. Increased magnesium levels have been shown to mitigate cardiovascular risk $[5,6]$.

In a systematic review and meta-analysis of randomized controlled trials, every $0.2 \mathrm{mmol} / \mathrm{L}$ increase in circulating magnesium was associated with a 30\% reduction in cardiovascular disease risk; there was also a trend toward lower risks of ischemic heart disease and fatal ischemic heart disease [5]. A separate meta-analysis demonstrated that increased dietary magnesium intake was associated with a decreased risk of heart failure and stroke [6].

The sodium glucose co-transporter 2 (SGLT2) inhibitor canagliflozin has demonstrated clinically meaningful improvements in glycemic control, body weight, and blood pressure, with a favorable tolerability profile in patients with type 2 diabetes [7]. Canagliflozin has also been shown to increase serum magnesium levels [8], with minimal changes in its fractional excretion [9]. We evaluated the effects of canagliflozin on serum magnesium in patients with type 2 diabetes and hypomagnesemia.

\section{METHODS}

\section{Study Design}

This post hoc analysis was based on pooled data from four 26-week, placebo-controlled, phase 3 studies $(N=2313)$ that evaluated canagliflozin 100 and $300 \mathrm{mg}$ in patients with type 2 diabetes (ClinicalTrials.gov Identifiers: NCT01081834, NCT01106677, NCT01106625, NCT01106690).

\section{Endpoints/Assessments}

Percentage change in serum magnesium at week 26 was evaluated in patients with baseline serum magnesium $<0.74$ and $\geq 0.74 \mathrm{mmol} / \mathrm{L}$ using data obtained from standard laboratory assessments during the individual trials. The proportion of patients with baseline serum magnesium $<0.74 \mathrm{mmol} / \mathrm{L}$ who achieved serum magnesium $\geq 0.74 \mathrm{mmol} / \mathrm{L}$ at week 26 was determined.

\section{Statistical Analyses}

Data were from the modified intent-to-treat population (mITT), which consisted of all randomized patients who received $\geq 1$ dose of study drug. The last observation carried forward approach was used to impute missing data at week 26. Percentage change from baseline in serum magnesium was analyzed using an analysis of covariance (ANCOVA) model, with treatment and study as fixed effects and the corresponding baseline serum magnesium value as a covariate. The model included terms for treatment (to assess treatment effect), baseline (to adjust for baseline differences), and study (to account for differences in the studies as the analysis was based on pooled data). Least squares (LS) mean differences and two-sided 95\% confidence intervals (CIs) were determined for each canagliflozin dose versus placebo. The categorical endpoint of the proportion of hypomagnesemic patients with serum magnesium $<0.74 \mathrm{mmol} / \mathrm{L}$ at baseline who achieved serum magnesium $\geq 0.74 \mathrm{mmol} /$ $\mathrm{L}$ at week 26 was analyzed using a logistic regression model, with treatment and study as fixed effects and baseline serum magnesium value as a covariate. Odds ratios (ORs) and 95\% CIs were estimated for the proportion of hypomagnesemic patients whose serum magnesium levels normalized at week 26 with canagliflozin versus placebo. Statistical testing of differences between canagliflozin and placebo was not prespecified for these analyses; therefore, $P$ values are not reported.

\section{Compliance with Ethics Guidelines}

All study procedures followed were in accordance with the ethical standards of the responsible committee on human experimentation (institutional and national) and with the Helsinki Declaration of 1964, as revised in 2013. 
Informed consent was obtained from all patients prior to their enrollment in the study.

\section{RESULTS}

\section{Patients}

Of 2313 patients in the mITT analysis set, mean baseline serum magnesium was $0.78 \mathrm{mmol} / \mathrm{L}$ (range $0.41-1.23 \mathrm{mmol} / \mathrm{L}[1-3 \mathrm{mg} / \mathrm{dL}]$ ). In the overall population, $18.3 \%(n=424)$ had serum magnesium $<0.74 \mathrm{mmol} / \mathrm{L}(<1.8 \mathrm{mg} / \mathrm{dL}$; hypomagnesemia $), \quad 80.7 \% \quad(n=1867)$ had serum magnesium $0.74-0.94 \mathrm{mmol} / \mathrm{L}(1.8-2.3 \mathrm{mg} / \mathrm{dL}$; normal magnesium), and $1.0 \%(n=22)$ had serum magnesium $>0.94 \mathrm{mmol} / \mathrm{L}(>2.3 \mathrm{mg} / \mathrm{dL}$; hypermagnesemia) at baseline; proportions were generally similar with canagliflozin 100 and $300 \mathrm{mg}$ and placebo, respectively, in each serum magnesium category (hypomagnesemia: $20.2 \%, 16.9 \%$, and $17.8 \%$; normal magnesium: $78.8 \%, 82.3 \%$, and $81.3 \%$; hypermagnesemia: $1.1 \%, 0.8 \%$, and $0.9 \%$ ). Baseline characteristics were generally balanced across groups in patients with baseline serum magnesium $<0.74$ and $\geq 0.74 \mathrm{mmol} / \mathrm{L}$ (because of the small number of patients with hypermagnesemia, data for all patients with serum magnesium $\geq 0.74 \mathrm{mmol} / \mathrm{L}$ were pooled; Table 1 ).

\section{Effects on Serum Magnesium}

In the overall population, LS mean percentage changes from baseline in serum magnesium at week 26 were $8.1 \%$ and $9.3 \%$ with canagliflozin 100 and $300 \mathrm{mg}$ versus $-0.4 \%$ with placebo [8]. Among patients with baseline serum magnesium $<0.74 \mathrm{mmol} / \mathrm{L}$, LS mean percentage changes in serum magnesium at week 26 were $17.0 \%, 19.0 \%$, and $3.9 \%$ with canagliflozin 100 and $300 \mathrm{mg}$ and placebo, respectively (differences [95\% CI] vs placebo of $13.0 \%[10.5,15.6]$ and $15.1 \%$ [12.4, 17.7]; Fig. 1). Among patients with baseline serum magnesium $\geq 0.74 \mathrm{mmol} / \mathrm{L}$, LS mean percentage changes in serum magnesium were $4.9 \%, 7.0 \%$, and $-1.4 \%$ with canagliflozin 100 and $300 \mathrm{mg}$ and placebo, respectively (differences [95\% CI] of 6.3\% [5.5,
7.2] and 8.4\% [7.6, 9.2]; Fig. 1). There were no patients with serum magnesium levels above the upper limit of normal $(>1.27 \mathrm{mmol} / \mathrm{L})$ in any treatment group at 26 weeks.

At week 26 in the canagliflozin 100 and $300 \mathrm{mg}$ and placebo groups, 59 (7.2\%), 33 (4.0\%), and $117(18.6 \%)$ patients had hypomagnesemia; 731 (88.7\%), $738(90.3 \%)$, and 505 $(80.4 \%)$ patients had normal serum magnesium levels; and $34(4.1 \%), 46(5.6 \%)$, and 6 (1.0\%) patients had hypermagnesemia, respectively. Overall, a higher proportion of patients with baseline serum magnesium $<0.74 \mathrm{mmol} / \mathrm{L}$ had serum magnesium $\geq 0.74 \mathrm{mmol} / \mathrm{L}$ at week 26 with canagliflozin 100 and $300 \mathrm{mg}$ versus placebo $(74.1 \%, 80.6 \%$, and $28.8 \%$, respectively; Fig. 2). For hypomagnesemic patients, the likelihood of achieving serum magnesium $\geq 0.74 \mathrm{mmol} / \mathrm{L}$ was 10 and 14 times greater with canagliflozin 100 and $300 \mathrm{mg}$ versus placebo.

\section{DISCUSSION}

Hypomagnesemia is common in patients with type 2 diabetes (14-48\%) and has been identified as an independent risk factor for cardiovascular disease and CKD [1-3]. In particular, hypomagnesemic individuals can develop ventricular arrhythmias, which may lead to serious cardiovascular outcomes, including sudden cardiac death [4, 10-12]. Evidence suggests that increases in circulating magnesium are associated with a lower risk of cardiovascular disease; this may be related to antiarrhythmic and anti-ischemic effects in the heart, as well as beneficial effects on endothelial tissue and vascular smooth muscle cells (e.g., enhanced vasodilation, reduced inflammation) [5]. In this analysis, canagliflozin treatment increased serum magnesium over 26 weeks and normalized magnesium levels in hypomagnesemic patients with type 2 diabetes.

Results from the current analysis are consistent with a recent meta-analysis of 18 randomized controlled trials of SGLT2 inhibitors in patients with type 2 diabetes, suggesting that the impact on serum magnesium levels may be a class effect [13]. Dose-dependent increases in magnesium were seen with canagliflozin 100 


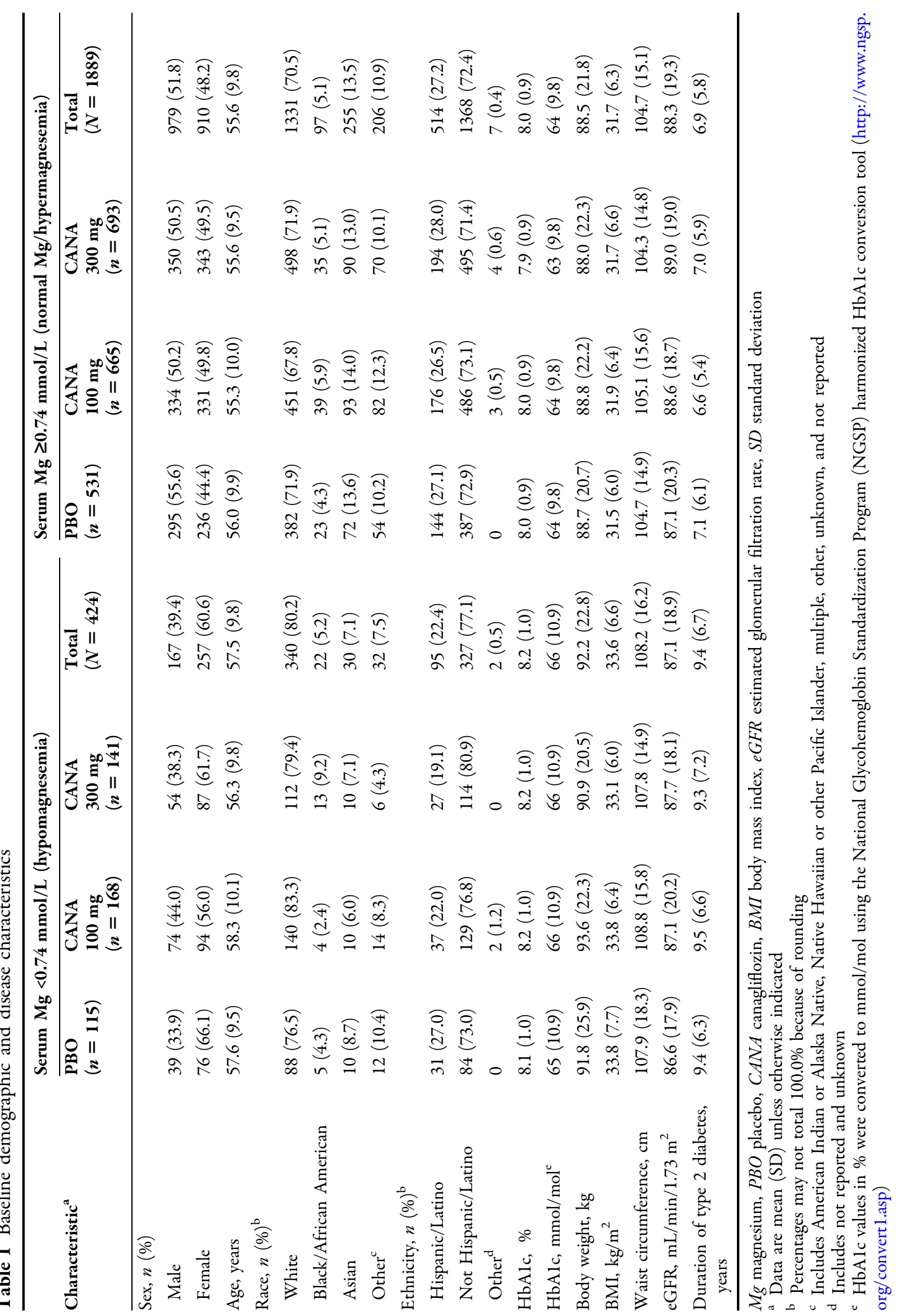




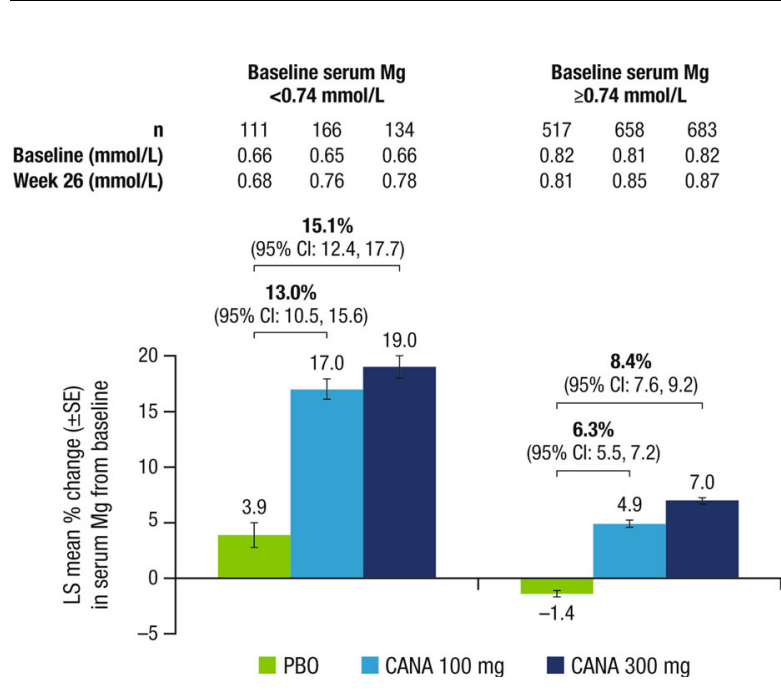

Fig. 1 Percentage change from baseline in serum magnesium at week 26. $M g$ magnesium, $C I$ confidence interval, $L S$ least squares, $S E$ standard error, $P B O$ placebo, $C A N A$ canagliflozin

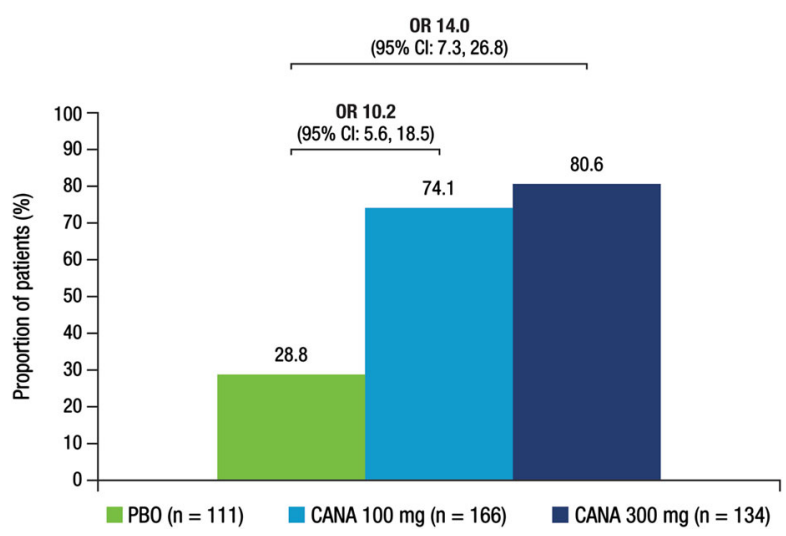

Fig. 2 Proportion of patients with baseline serum magnesium $<0.74 \mathrm{mmol} / \mathrm{L}$ who achieved serum magnesium $\geq 0.74 \mathrm{mmol} / \mathrm{L}$ at week 26 . $O R$ odds ratio, $C I$ confidence interval, $P B O$ placebo, $C A N A$ canagliflozin

and $300 \mathrm{mg}$ (0.06 vs $0.09 \mathrm{mmol} / \mathrm{L})$; similar changes were observed with dapagliflozin $10 \mathrm{mg}(0.1 \mathrm{mmol} / \mathrm{L})$, empagliflozin 10 and $25 \mathrm{mg}$ (0.04 vs $0.07 \mathrm{mmol} / \mathrm{L})$, and ipragliflozin $50 \mathrm{mg} \quad(0.05 \mathrm{mmol} / \mathrm{L})$ [13]. Of note, the meta-analysis results were based on data from patients with normal renal function, but a sensitivity analysis including data from two trials in patients with CKD showed that the overall findings were robust [13]. Canagliflozin has also demonstrated serum magnesium improvements in patients with type 2 diabetes and CKD
(eGFR $\geq 30$ and $<50 \mathrm{~mL} / \mathrm{min} / 1.73 \mathrm{~m}^{2}$ ) $[14,15]$. Over 26 weeks of treatment, increases in serum magnesium were seen with canagliflozin 100 and $300 \mathrm{mg}(9.4 \%$ vs $14.6 \%)$, whereas no change was seen with placebo $(0.0 \%$; baseline, $0.8 \mathrm{mmol} / \mathrm{L}$ for all) [14].

Abnormal elevations of serum magnesium have been linked to adverse cardiovascular outcomes in certain populations (e.g., heart failure, critically ill, or on hemodialysis) [16-18]. In this analysis, there was a small increase from baseline in the number of patients with hypermagnesemia in the canagliflozin groups at week 26 , but no patients had serum magnesium levels above the upper limit of normal $(>1.27 \mathrm{mmol} / \mathrm{L})$. It is important to note that canagliflozin is not indicated for use in patients with severe renal impairment or end-stage renal disease or who are on dialysis [19].

The mechanism for the observed effects of canagliflozin on serum magnesium is unclear. It is unlikely that the increases in serum magnesium seen with canagliflozin are attributable to glycemic improvements, as increases in serum magnesium have not been reported with other antihyperglycemic agents, including sitagliptin and glimepiride, in head-to-head studies with canagliflozin (data on file and [20]). A possible explanation is that canagliflozin treatment is associated with improvements in insulin sensitivity (measured by changes in glucosuriacorrected oral glucose insulin sensitivity [OGIS ${ }_{\mathrm{c}}$ ] index values [21]), which may increase magnesium levels by interrupting the cycle of hypomagnesemia induced by insulin resistance. And while bone storage is involved in magnesium homeostasis, it is unlikely that increased magnesium levels are due to leaching from bone, as bone mineral density remains relatively unchanged with canagliflozin treatment over 2 years [22]. Another consideration is that SGLT2 inhibitors have been shown to increase plasma glucagon levels [23, 24], which may increase magnesium reabsorption in the distal convoluted tubule (DCT) [25]. Finally, the observed increase in serum magnesium may be related to canagliflozin acting on ion channels in the DCT (e.g., TRPM6/TRPM7), which have been found to modulate urinary magnesium excretion [26]. 
This analysis was strengthened by the use of a large, pooled dataset. At baseline, approximately $18 \%$ of patients were hypomagnesemic, which is representative of the general type 2 diabetes population [1]. One potential limitation of this analysis was that there were no restrictions on the use of drugs known to alter magnesium homeostasis (e.g., diuretics, proton pump inhibitors, antimicrobials) [1], which may have impacted serum magnesium levels. However, canagliflozin treatment has demonstrated consistent increases in serum magnesium across a broad range of patients with type 2 diabetes with varying degrees of background diuretic use, including the current analysis (approximately $23 \%$ of patients were on diuretics) and a separate analysis of patients with eGFR $\geq 45$ and $<60 \mathrm{~mL} / \mathrm{min} / 1.73 \mathrm{~m}^{2}$ (approximately $50 \%$ of patients were on diuretics) [8]. Another potential limitation was that intracellular magnesium levels were not measured. Intracellular magnesium has been proposed to better reflect magnesium homeostasis than serum magnesium, as approximately 99\% of magnesium is stored within bone, muscle, and other soft tissues; however, serum magnesium remains widely used and may be a more practical measure for clinicians who treat patients with type 2 diabetes.

\section{CONCLUSIONS}

Canagliflozin was associated with normalization of serum magnesium levels in hypomagnesemic patients with type 2 diabetes, which may lead to improved cardiometabolic outcomes and a reduced risk of arrhythmia. Results from ongoing, large-scale outcomes trials will help to define the potential benefits of canagliflozin on cardiovascular health and risk of CKD.

\section{ACKNOWLEDGEMENTS}

This analysis was funded by Janssen Scientific Affairs, LLC, and was based on data from studies supported by Janssen Research \& Development, LLC. Medical writing support, provided by Alaina Mitsch, PhD, of MedErgy, and article processing charges were funded by Janssen Global Services, LLC. Richard E. Gilbert is the Canada Research Chair in Diabetes Complications and this work was supported, in part, by the Canada Research Chairs Program. Richard E. Gilbert and Christian Mende contributed to the interpretation of data and the development of the manuscript. Ujjwala Vijapurkar and Michael J. Davies contributed to the analysis and interpretation of the data, and the development of the manuscript. Sue Sha and Mehul Desai contributed to the design and conduct of the original studies used in this pooled analysis; the acquisition, analysis, and interpretation of the data; and the development of the manuscript. All named authors meet the International Committee of Medical Journal Editors (ICMJE) criteria for authorship for this manuscript, take responsibility for the integrity of the work as a whole, and have given final approval to the version to be published. These data were presented, in part, at the 76th Scientific Sessions of the American Diabetes Association on June 10-14, 2016 in New Orleans, Louisiana and at the 52nd Annual Meeting of the European Association for the Study of Diabetes (EASD) on September 12-16, 2016 in Munich, Germany. Canagliflozin has been developed by Janssen Research \& Development, LLC, in collaboration with Mitsubishi Tanabe Pharma Corporation.

Disclosures. Richard E. Gilbert has received honoraria for CME lectures and advisory board membership from Janssen, AstraZeneca, and Boehringer Ingelheim and has received research funding to his institution from AstraZeneca and Boehringer Ingelheim. Christian Mende has served as a scientific advisor for Islet Science (Biotech) and has served on speaker's bureaus for Janssen, AstraZeneca, and Forest. Ujjwala Vijapurkar is a full-time employee of Janssen Research \& Development, LLC. Sue Sha is a full-time employee of Janssen Research \& Development, LLC. Mehul Desai is a full-time employee of Janssen Research \& Development, LLC. Michael J. Davies is a full-time employee of Janssen Scientific Affairs, LLC.

Compliance with Ethics Guidelines. All study procedures followed were in accordance 
with the ethical standards of the responsible committee on human experimentation (institutional and national) and with the Helsinki Declaration of 1964, as revised in 2013. Informed consent was obtained from all patients prior to their enrollment in the study.

Data Availability. The datasets analyzed for the current analysis are available from the corresponding author on reasonable request.

Open Access. This article is distributed under the terms of the Creative Commons Attribution-NonCommercial 4.0 International License (http://creativecommons.org/licenses/ by-nc/4.0/), which permits any noncommercial use, distribution, and reproduction in any medium, provided you give appropriate credit to the original author(s) and the source, provide a link to the Creative Commons license, and indicate if changes were made.

\section{REFERENCES}

1. Gommers LM, Hoenderop JG, Bindels RJ, de Baaij JH. Hypomagnesemia in type 2 diabetes: a vicious circle? Diabetes. 2016;65:3-13.

2. Tin A, Grams ME, Maruthur NM, et al. Results from the Atherosclerosis Risk in Communities study suggest that low serum magnesium is associated with incident kidney disease. Kidney Int. 2015;87:820-7.

3. Van Laecke S, Nagler EV, Verbeke F, Van Biesen W, Vanholder R. Hypomagnesemia and the risk of death and GFR decline in chronic kidney disease. Am J Med. 2013;126:825-31.

4. Del Gobbo LC, Song Y, Poirier P, Dewailly E, Elin RJ, Egeland GM. Low serum magnesium concentrations are associated with a high prevalence of premature ventricular complexes in obese adults with type 2 diabetes. Cardiovasc Diabetol. 2012;11:23.

5. Del Gobbo LC, Imamura F, Wu JH, de Oliveira Otto MC, Chiuve SE, Mozaffarian D. Circulating and dietary magnesium and risk of cardiovascular disease: a systematic review and meta-analysis of prospective studies. Am J Clin Nutr. 2013;98:160-73.

6. Fang X, Wang K, Han D, et al. Dietary magnesium intake and the risk of cardiovascular disease, type 2 diabetes, and all-cause mortality: a dose-response meta-analysis of prospective cohort studies. BMC Med. 2016;14:210.

7. Rosenthal N, Meininger G, Ways $\mathrm{K}$, et al. Canagliflozin: a sodium glucose co-transporter 2 inhibitor for the treatment of type 2 diabetes mellitus. Ann N Y Acad Sci. 2015;1358:28-43.

8. Weir MR, Kline I, Xie J, Edwards R, Usiskin K. Effect of canagliflozin on serum electrolytes in patients with type 2 diabetes in relation to estimated glomerular filtration rate (eGFR). Curr Med Res Opin. 2014;30:1759-68.

9. Devineni D, Vaccaro N, Polidori D, Rusch S, Wajs E. Effects of hydrochlorothiazide on the pharmacokinetics, pharmacodynamics, and tolerability of canagliflozin, a sodium glucose co-transporter 2 inhibitor, in healthy participants. Clin Ther. 2014;36:698-710.

10. Fiset C, Kargacin ME, Kondo CS, Lester WM, Duff HJ. Hypomagnesemia: characterization of a model of sudden cardiac death. J Am Coll Cardiol. 1996;27:1771-6.

11. Whang R, Hampton EM, Whang DD. Magnesium homeostasis and clinical disorders of magnesium deficiency. Ann Pharmacother. 1994;28:220-6.

12. Sjögren A, Edvinsson L, Fallgren B. Magnesium deficiency in coronary artery disease and cardiac arrhythmias. J Intern Med. 1989;226:213-22.

13. Tang $H$, Zhang $X$, Zhang J, et al. Elevated serum magnesium associated with SGLT2 inhibitor use in type 2 diabetes patients: a meta-analysis of randomised controlled trials. Diabetologia. 2016;59:2546-51.

14. Yale JF, Bakris G, Cariou B, et al. Efficacy and safety of canagliflozin in subjects with type 2 diabetes and chronic kidney disease. Diabetes Obes Metab. 2013;15:463-73.

15. Yale JF, Bakris G, Cariou B, et al. Efficacy and safety of canagliflozin over 52 weeks in patients with type 2 diabetes mellitus and chronic kidney disease. Diabetes Obes Metab. 2014;16:1016-27.

16. Lacson E Jr, Wang W, Ma L, Passlick-Deetjen J. Serum magnesium and mortality in hemodialysis patients in the United States: a cohort study. Am J Kidney Dis. 2015;66:1056-66.

17. Haider D, Lindner G, Ahmad S, et al. Hypermagnesemia is a strong independent risk factor for mortality in critically ill patients: results from a cross-sectional study. Eur J Intern Med. 2015;26:504-7. 
18. Corbi G, Acanfora D, Iannuzzi GL, et al. Hypermagnesemia predicts mortality in elderly with congestive heart disease: relationship with laxative and antacid use. Rejuvenation Res. 2008;11:129-38.

19. INVOKANA $^{\circledR}$ (canagliflozin) tablets, for oral use [package insert]. Titusville: Janssen Pharmaceuticals; 2016.

20. Leiter LA, Yoon KH, Arias P, et al. Canagliflozin provides durable glycemic improvements and body weight reduction over 104 weeks versus glimepiride in patients with type 2 diabetes on metformin: a randomized, double-blind, phase 3 study. Diabetes Care. 2015;38:355-64.

21. Polidori D, Mari A, Ferrannini E. Canagliflozin, a sodium glucose co-transporter 2 inhibitor, improves model-based indices of beta cell function in patients with type 2 diabetes. Diabetologia. 2014;57:891-901.

22. Bilezikian JP, Watts NB, Usiskin K, et al. Evaluation of bone mineral density and bone biomarkers in patients with type 2 diabetes mellitus treated with canagliflozin, a sodium glucose co-transporter 2 inhibitor. J Clin Endocrinol Metab. 2016;101:44-51.

23. Ferrannini E, Muscelli E, Frascerra S, et al. Metabolic response to sodium-glucose cotransporter 2 inhibition in type 2 diabetic patients. J Clin Invest. 2014;124:499-508.

24. Merovci A, Solis-Herrera C, Daniele G, et al. Dapagliflozin improves muscle insulin sensitivity but enhances endogenous glucose production. J Clin Invest. 2014;124:509-14.

25. Dai LJ, Ritchie G, Kerstan D, Kang HS, Cole DE, Quamme GA. Magnesium transport in the renal distal convoluted tubule. Physiol Rev. 2001;81:51-84.

26. Schlingmann KP, Waldegger S, Konrad M, Chubanov V, Gudermann T. TRPM6 and TRPM7-gatekeepers of human magnesium metabolism. Biochim Biophys Acta. 2007;1772:813-21. 